\title{
Response of RadFET Dosimeters to High Fluences of Fast Neutrons
}

\author{
F. Ravotti, Student Member, IEEE, M. Glaser, M. Moll, Ch. Ilgner, Member, IEEE, B. Camanzi, and \\ A. G. Holmes-Siedle, Senior Member, IEEE
}

\begin{abstract}
We present irradiation experiments carried out on RadFETs in the high-intensity T2 neutron beam at the CRC-UCL in Belgium. The aim of the test was to characterize the neutron response of RadFETs in view of their use as an integrated part of a radiation-monitoring sensor for the CERN Large Hadron Collider (LHC) experiments. Two types of RadFETs were investigated up to a total neutron fluence of $3 \times 10^{14} \mathrm{~cm}^{-2}$ corresponding to a deposited dose of $744 \mathrm{~Gy}$ in silicon. The responses of bare devices to neutrons are compared to the commonly used reference measurements with gamma rays. It is found that the gamma ray calibration cannot directly be adopted to convert the RadFET signals into neutron dose. In a second experiment, the influence of a plastic packaging, simulated by polyethylene slabs of different thicknesses, was tested in the neutron beam and compared to GEANT4 Monte Carlo simulations. An increase of the RadFET neutron sensitivity by a factor of up to 7 due to the packaging is found. The influence of these findings on the conception of the radiation-monitoring sensor is discussed.
\end{abstract}

Index Terms-Dosimetry, gamma-ray detectors, neutron beams, RadFETs, radiation monitoring.

\section{INTRODUCTION}

$\mathbf{T}$ HE response of MOSFET dosimeters (RadFETs) to different particle environments is under investigation at CERN (European Organization for Nuclear Research) with the aim to apply this technology for the radiation monitoring of the Compact Muon Solenoid (CMS) experiment [1] and possibly also the other LHC experiments [2].

In CMS, a strong mixed radiation field composed of neutrons, photons and charged hadrons, is expected and has been calculated in detail by Monte Carlo simulations [3]. At large radii from the interaction point $(>2 \mathrm{~m})$ this complex field is dominated by fast neutrons. In some locations a fast neutron fluence of more than $10^{14} \mathrm{~cm}^{-2}$ is expected over a 10 -year period.

To monitor the ionizing and nonionizing components of the radiation field in CMS, an integrated sensor based on a combination of RadFET and Optically Stimulated Luminescence (OSL)

Manuscript received November 2, 2004; revised April 11, 2005.

F. Ravotti is with the Department TS-LEA-RAD, CERN, Geneva 23, $\mathrm{CH}-1211$, Switzerland. He is also with $\mathrm{CEM}^{2}$, Université Montpellier II, 34095 Montpellier Cedex 5, France (e-mail: Federico.Ravotti@cern.ch).

M. Glaser and M. Moll are with the Department PH-DT2-SD, CERN, Geneva 23, $\mathrm{CH}-1211$, Switzerland.

C. Ilgner is with the Department TS-LEA-RAD, CERN, Geneva 23, CH-1211, Switzerland.

B. Camanzi is with PPD Rutherford Appleton Laboratory, Chilton Didcot, Oxon OX11 0QX, England.

A. G. Holmes-Siedle is with REM Oxford Ltd., Eynsham, Witney, OX29 4PD, U.K.

Digital Object Identifier 10.1109/TNS.2005.852709 dosimeters as well as $p-i-n$ diodes has already been proposed elsewhere [4], [5].

In a first test [6], significant differences in the response of unpackaged (i.e., bare die) and packaged RadFETs were observed in the mixed gamma/neutron environment of the IRRAD2 facility at the CERN Proton-Synchrotron (PS) accelerator [7]. Therefore, the influence of the packaging, especially in a fast neutron field, has become a crucial issue which will influence the design of the above mentioned radiation monitor sensor.

In this paper, we describe experimental results obtained with different MOSFET devices irradiated at the high-intensity T2 pure neutron source at the Cyclotron Research Centre (CRC) of the Catholic University of Louvain-La-Neuve (UCL) in Belgium [8]. Bare die chips as well as chips covered with Polyethylene (PE) slabs of different thicknesses were tested in order to simulate the chip's plastic packaging. The results are compared to the predictions of a Monte Carlo simulation using the GEANT4 package [9].

Furthermore, the data obtained with the unpackaged devices in the UCL neutron beam are compared with gamma ray reference measurements and data previously obtained by Blamires et al. [10] on $15-\mathrm{MeV}$ neutrons.

\section{EXPERIMENT}

\section{A. Devices Tested}

RadFET dosimeters are p-channel MOS transistors that respond to ionizing dose via a charge build-up in the $\mathrm{SiO}_{2}$ layer of the device. The growth of the threshold voltage $\mathrm{V}_{\mathrm{th}}$ of the transistor (more precisely the voltage for a given drain current) is a smooth but complex function of the deposited dose [11], [12]. A voltage $\mathrm{V}_{\mathrm{I}}$ can be applied to the gate of the device during exposure in order to influence its response. For $\mathrm{V}_{\mathrm{I}}=0 \mathrm{~V}$ (exposure mode chosen in this work and usually called zero bias mode) the expected response of the voltage shift $\Delta \mathrm{V}_{\text {th }}$ follows a power-law:

$$
-\Delta V_{t h}=a \cdot D^{b}
$$

where $a$ and $b$ are experimental parameters. Usually it is not possible to find values for $a$ and $b$ which are valid throughout a large dose range; in such cases pairs of $a$ and $b$ are given for different dose ranges. For small doses $b$ is usually close to one while for high doses much smaller values are found. Parameter $a$ in fact contains several constant device parameters such as oxide thickness, number, and cross section of hole-traps in the gate oxide. 


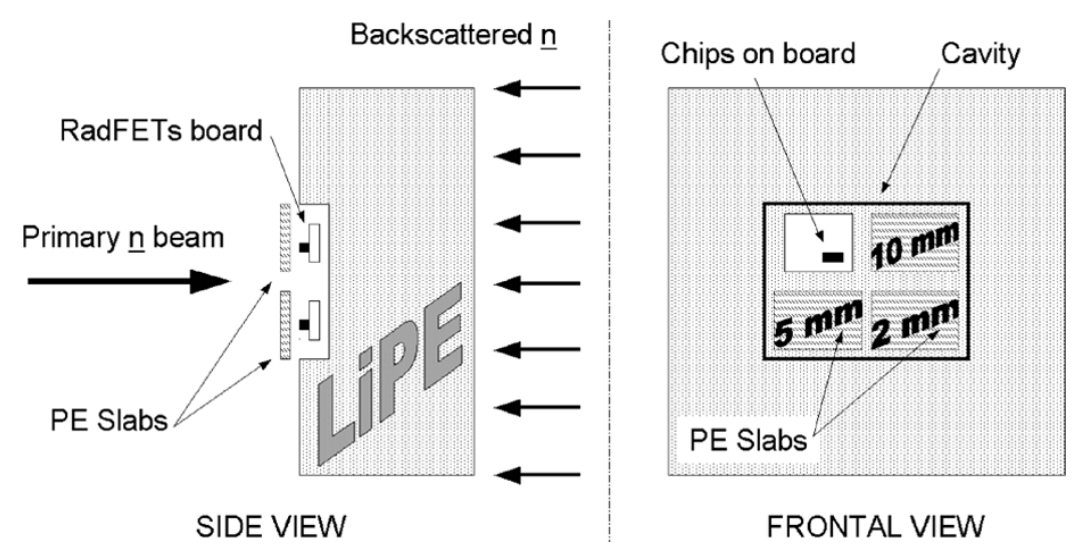

Fig. 1. Sketch of the dosimeter assembly. LiPE stands for "lithium doped polyethylene," used as shielding against back-scattered neutrons in the beam-line.

RadFETs are integrating dosimeters. They are usually used where regular measurements of integrated doses are required within limited volumes [13]. The RadFET dosimeters used for our test were obtained from two different suppliers: NMRC, Ireland [14] and REM, England [15]. Bare die MOSFET chips with different oxide thicknesses $\left(t_{\mathrm{ox}}\right)$ of $0.40 \mu \mathrm{m}$ (ESAPMOS04) and $0.25 \mu \mathrm{m}$ (TOT-501C type $\mathrm{K}$ ) were supplied, respectively.

A third type of RadFET, provided by Thomson and Nielsen Electronics Ltd. (T\&N), Canada [16], was used for the measurement of the gamma background during the neutron irradiation. These devices, with oxide thicknesses varying from $0.10 \mu \mathrm{m}$ to $0.50 \mu \mathrm{m}$, were supplied in an 8-pin Dual-In-line (DIP) plastic package.

\section{B. Irradiation Setup}

1) Neutron Irradiation: The T2 high-intensity neutron beam at the CRC is a secondary beam based on the nuclear reaction ${ }^{9} \mathrm{Be}(\mathrm{d}, \mathrm{n}){ }^{10} \mathrm{~B}$. The $50-\mathrm{MeV}$ primary deuteron beam of the UCL Isochronous Cyclotron that hits the beryllium target is used to generate a neutron field with energy spectrum ranging from about 15 to $25 \mathrm{MeV}$ and maximum that lies at $20.4 \mathrm{MeV}$ [17]. Deuteron bunches of 4-ns width and with a repetition period of about $80 \mathrm{~ns}$ are making the neutron beam quasi-continuous in time.

The samples were mounted with the sensing surface perpendicular to the beam and exposed to a flux of $1.96 \times 10^{13} \mathrm{~cm}^{-2}$. $\mathrm{h}^{-1}$ corresponding to a total neutron fluence $(\Phi)$ of $3.04 \times$ $10^{14} \mathrm{~cm}^{-2}$ cumulated in $15.5 \mathrm{~h}$ of irradiation. Over the irradiation spot of $4.0-\mathrm{cm}$ radius, the beam intensity varied smoothly by about $20 \%$.

In terms of fluence, the contamination of the beam with gamma rays from neutron interactions with the material of the filters surrounding the target has been measured to be $2.4 \%$ [18].

Four thin printed circuit boards (PCBs), of $4.2 \mathrm{~cm}^{2}$ area containing six bare die RadFETs each, were produced and assembled as shown in Fig. 1. The six devices (three REM and three NMRC) were mounted in an area of a few square millimeters in one corner of a metallized square as indicated by $(a)$ in Fig. 2 . Care was taken to position the four PCBs at the same distance from the center of the beam.

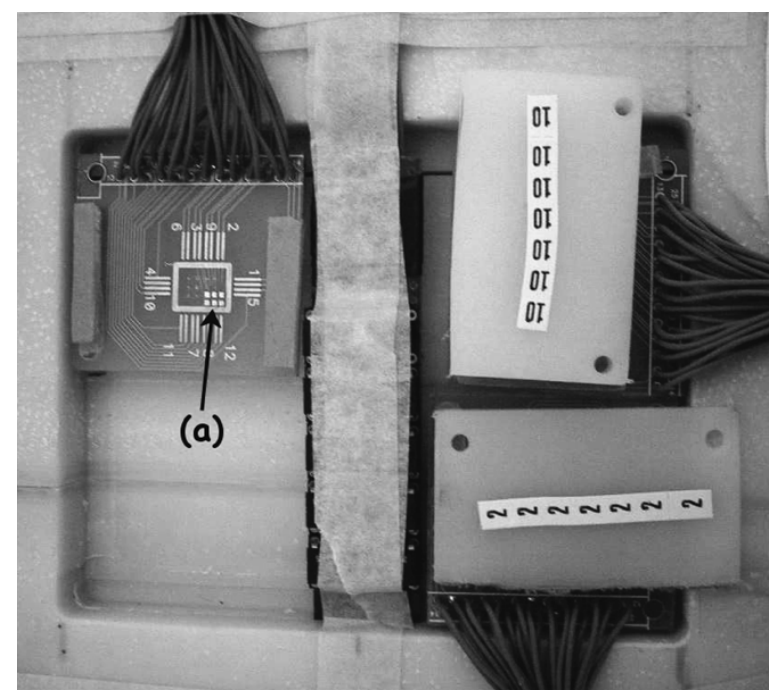

Fig. 2. Experimental setup as installed in the T2 beam-line. Six RadFET dies can be seen in the lower right-hand corner of a metallized square indicated by "a."

The device-to-device response for all the dosimeter series varied only by a few percent, proving a good reproducibility of the measured results.

One board was exposed directly to the neutron beam while the other three were covered with polyethylene (PE) slabs of different thicknesses $(2,5$, and $10 \mathrm{~mm})$ in order to simulate different plastic packaging. Fig. 2, taken during the assembly, shows two PE slabs already positioned on top of two PCBs (right-hand side) and the uncovered PCB.

The assembly of four boards was inserted into a cavity worked into a block of lithium-doped polyethylene (LiPE). The dimensions of the LiPE block and the cavity were $20 \mathrm{~cm} \times 20 \mathrm{~cm} \times 6.5 \mathrm{~cm}$ and $11 \mathrm{~cm} \times 9 \mathrm{~cm} \times 1 \mathrm{~cm}$, respectively (see Fig. 1).

The LiPE material, developed as neutron shielding for the ATLAS detector at CERN [19], was used to shield backscattered neutrons generated by interaction of the primary neutron beam with surrounding materials in the irradiation area. The Hydrogen contained in PE is slowing down neutrons, while the Lithium is capturing them via the reaction ${ }^{6} \mathrm{Li}(\mathrm{n}, \alpha){ }^{3} \mathrm{H}$, that is not accompanied by gamma ray emission [20]. 
To allow the determination of the low gamma ray contamination of the beam, 3 T\&N RadFETs were placed in a LiPE box of smaller volume $\left(1500 \mathrm{~cm}^{3}\right)$, placed downstream in the irradiation area, $1.80 \mathrm{~m}$ away from the samples in the beam.

2) Gamma Irradiation: The ${ }^{137} \mathrm{Cs}$ irradiations were performed at the CERN Gamma Irradiation Facility (GIF) [21]. In this facility a radioactive Cesium source of $652 \mathrm{GBq}$ (September 2002) is used. Its intensity was measured, before RadFET's exposure, by means of a calibrated PTW ionization chamber [22] of $1 \mathrm{~cm}^{3}$ volume.

\section{RadFETs Readout}

All readings were taken in zero bias mode during irradiation. The readout protocol was designed to accommodate the read-time instability (i.e., increase of the signal over time due to border states) [12]. The current values applied to the devices were chosen according to the producer specifications and were $10 \mu \mathrm{A}$ and $160 \mu \mathrm{A}$ for the NMRC and REM devices, respectively.

The DAQ system consisted of a 40-channel Agilent Switch Matrix and a Keithley Source Meter 2410. The Source Meter was used as current generator and also to record the MOSFETs' threshold voltage. Both units, placed outside the irradiation area, were under PC control by means of a LabVIEW program. The RadFETs were connected via a $16 \mathrm{~m}$ long twisted-pair cable to the Switch Matrix.

\section{GAMMA RADIATION RESPONSES FOR RADFETS}

To allow the calculation of the RadFET neutron responses presented in Section IV, a calibration describing the device responses to gamma radiation is needed.

RadFETs response to ${ }^{60} \mathrm{Co}$ gamma-rays is the most frequently used calibration to convert the RadFET signal into absorbed dose.

In the present work, the $\Delta V_{\text {th }}$ versus dose curves for gamma rays were obtained combining the data of an irradiation carried out at CERN using a ${ }^{137} \mathrm{Cs}$ source (see Section II-B-2) and ${ }^{60} \mathrm{Co}$ data provided by the manufacturer [23], [24]. The above mentioned reference curves were finally fitted in the dose range of interest using (1).

Fig. 3 shows the gamma calibration for the REM and NMRC devices over four decades of dose ranging from $10^{-1} \mathrm{~Gy}_{\mathrm{Si}}$ to $10^{3} \mathrm{~Gy}_{\mathrm{Si}}$. The experimental data are represented with circle and square markers (filled for ${ }^{60} \mathrm{Co}$ and empty for ${ }^{137} \mathrm{Cs}$ ), as well as the power-law parameterization obtained from a least-square fit to the data in the range from $0.1 \mathrm{~Gy}_{\mathrm{Si}}$ to $20 \mathrm{~Gy}_{\mathrm{Si}}$.

Analogous measurements in the dose range from 0.1 to $20 \mathrm{~Gy}_{\mathrm{Si}}$ were performed for the T\&N devices at the CERN GIF facility. Table I shows the values of the coefficient $a$ and $b$ of (1) obtained for all RadFETs used in this study.

\section{RESULTS}

\section{A. Gamma-Ray Contamination Measurement}

The signals measured with the three T\&N RadFETs outside the beam were converted into absorbed doses at the irradiation position by means of the parameters given in Table I. The T\&N

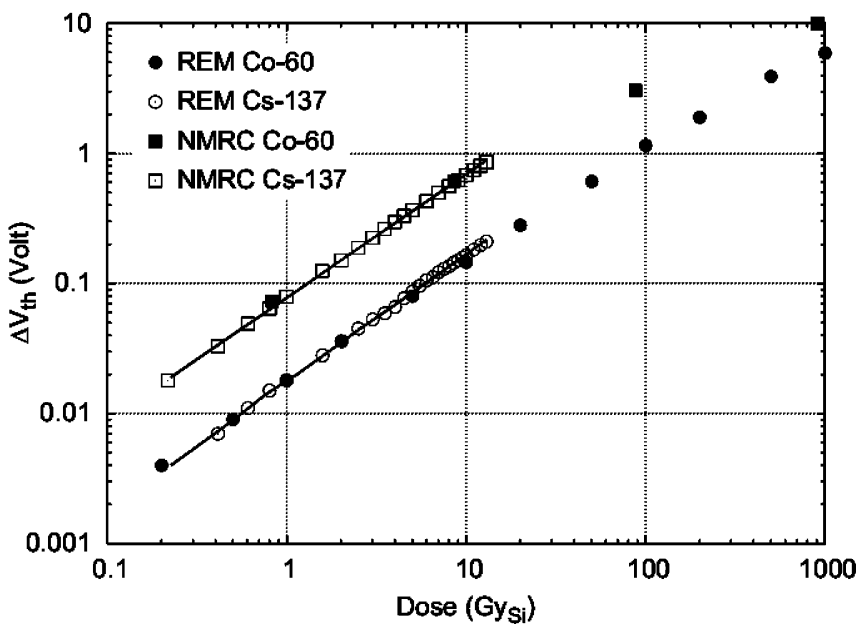

Fig. 3. Gamma ray reference curves for REM and NMRC RadFETs obtained with ${ }^{60} \mathrm{Co}(\mathrm{E} \gamma=1.3 \mathrm{MeV}$, filled markers $)$ and ${ }^{137} \mathrm{Cs}(\mathrm{E} \gamma=660 \mathrm{keV}$, empty markers). The least-square fits of the data in the range 0.1 to $20 \mathrm{~Gy}$ were also reported. Devices exposed at $V_{I}=0 \mathrm{~V}$.

TABLE I

Gamma CALIBRATION For RADFETs IN THE RANGe 0.1 To $20 \mathrm{~Gy}$. DEVICES EXPOSED AT $\mathrm{V}_{\mathrm{I}}=0 \mathrm{~V}$

\begin{tabular}{ccc}
\hline & $a\left[\mathrm{~V} / \mathrm{Gy}_{\mathrm{Si}}\right]$ & $b$ \\
\hline $\mathrm{REM}\left(\mathrm{t}_{\mathrm{ox}}=0.25 \mu \mathrm{m}\right)$ & 0.018 & 0.9699 \\
\hline $\mathrm{NMRC}\left(\mathrm{t}_{\mathrm{ox}}=0.40 \mu \mathrm{m}\right)$ & 0.0782 & 0.9472 \\
\hline $\mathrm{T} \& \mathrm{~N}\left(\mathrm{t}_{\mathrm{ox}}=0.10 \mu \mathrm{m}\right)$ & 0.0091 & 1.0374 \\
\hline $\mathrm{T} \& \mathrm{~N}\left(\mathrm{t}_{\mathrm{ox}}=0.25 \mu \mathrm{m}\right)$ & 0.041 & 0.9497 \\
\hline $\mathrm{T} \& \mathrm{~N}\left(\mathrm{t}_{\mathrm{ox}}=0.50 \mu \mathrm{m}\right)$ & 0.1142 & 0.9123 \\
\hline
\end{tabular}

devices placed in the LiPE box outside the beam and, therefore, measuring only the gamma-ray background in the irradiation area, received a dose of $5.62 \mathrm{~Gy}_{\mathrm{Si}}$. The RMS variation on this measurement was $\pm 3 \%$. In the calculation of the gamma dose, the weak attenuation of the photons in air was taken into account.

\section{B. Response of Bare Die RadFETs to Pure Neutron Beam}

Taking into account the above measurements of gamma-ray contamination, the REM and NMRC RadFET responses to the 20.4 MeV neutrons were calculated as follows.

The neutron spectrum of the T2 beam [18] was folded with the absorbed ionizing-dose factors $d_{f}(E)$ simulated for thin semiconductor devices in a similar high-energy neutron field [25] resulting in an averaged $d_{f}$ of $2.47 \times 10^{-12} \mathrm{~Gy} \cdot \mathrm{cm}^{2}$. In this way the cumulated total neutron fluence of $3.04 \times 10^{14} \mathrm{~cm}^{-2}$ was converted into a dose in Silicon of about $744 \mathrm{~Gy}_{\mathrm{Si}}$.

Using the parameterization given in Table I and the measured gamma ray background, the expected shift of the threshold voltage due to gamma rays for the NMRC and the REM devices were calculated for each reading. By subtracting these values from the measured threshold voltage shift it was possible to obtain the RadFET response to neutrons.

In Fig. 4 the markers are the neutron responses obtained with the above procedure for the bare die devices. For comparison also the gamma ray responses of Fig. 3, have been plotted as lines (dotted line for REM, solid line for NMRC). The curves 


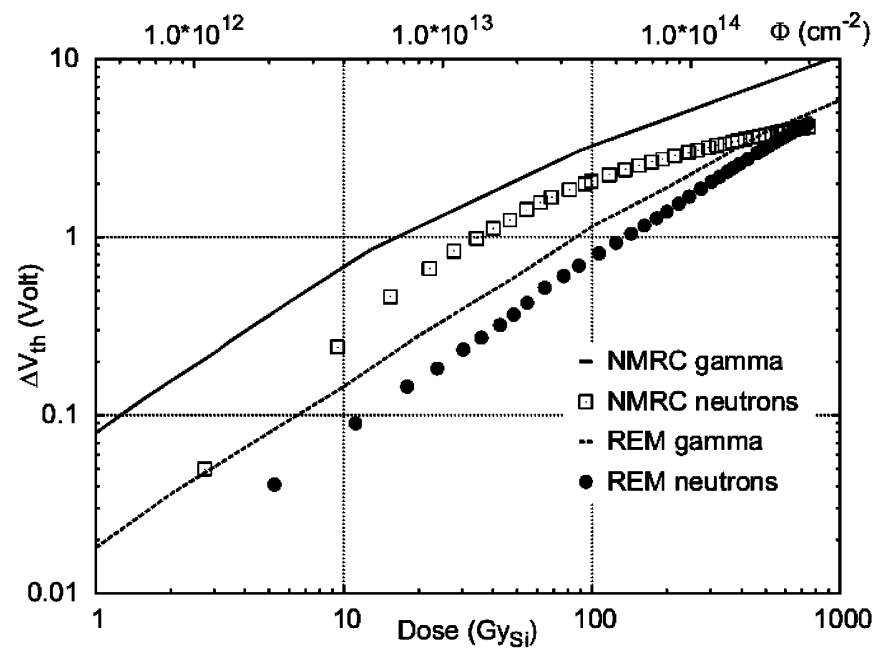

Fig. 4. Responses of RadFETs exposed to the neutron beam without a front absorber (markers) compared to the gamma response (lines, see also Fig. 3). The open data points refer to NMRC devices, while the filled ones are referred to REM samples. Devices exposed at $\mathrm{V}_{\mathrm{I}}=0 \mathrm{~V}$.

TABLE II

NEUTRON SENSITIVITIES OF BARE-Die RADFETs DEVICES EXPOSED AT $\mathrm{V}_{\mathrm{I}}=0 \mathrm{~V}$

\begin{tabular}{ccc}
\hline REM & $\begin{array}{c}\text { Low Dose Range } \\
(1-50 \mathrm{~Gy}) \\
{[\mathrm{mV} / \mathrm{Gy}]}\end{array}$ & $\begin{array}{c}\text { High Dose Range } \\
(600-744 \mathrm{~Gy}) \\
{[\mathrm{mV} / \mathrm{Gy}]}\end{array}$ \\
\hline Neutron & 7.64 & 4.7 \\
\hline Gamma & 12.3 & 4.9 \\
\hline & & \\
\hline \multirow{3}{*}{ NMRC } & Low Dose Range & High Dose Range \\
& $(1-50 \mathrm{~Gy})$ & $(600-744 \mathrm{~Gy})$ \\
{$[\mathrm{mV} / \mathrm{Gy}]$} & 1.6 \\
\hline Neutron & 26.9 & 8.5 \\
\hline Gamma & 66.8 & \\
\hline
\end{tabular}

of Fig. 4 are plotted as function of both absorbed dose in Silicon (lower $x$-axis) and total neutron fluence (upper $\mathrm{x}$-axis). Table II summarizes the measured sensitivities $(\mathrm{mV} / \mathrm{Gy})$ for low $\left(1-50 \mathrm{~Gy}_{\mathrm{Si}}\right)$ and high $\left(600-744 \mathrm{~Gy}_{\mathrm{Si}}\right)$ doses for gamma rays and neutrons.

\section{Packaging Influence on RadFET Response}

For the PE covered samples the data were treated as for the bare die samples presented in Section IV-B.

In Fig. 5 and Fig. 6 the responses of the REM and NMRC devices covered with different $P E$ slabs of increasing thicknesses from $2 \mathrm{~mm}$ to $10 \mathrm{~mm}$ are plotted in linear scale as a function of the total neutron fluence.

Square, triangular, and diamond empty markers represent in both pictures the PE slabs of 2-, 5-, and 10-mm thickness, respectively. To compare the influence of the slabs on the device's response, the data of the uncovered bare die devices are also plotted in the figures (filled markers).

Finally, in Table III the sensitivity enhancements measured for the devices covered by PE slabs, with respect to the bare-die samples, are summarized. In analogy with Table II the relative sensitivities for low $\left(0.5\right.$ to $\left.3 \times 10^{13} \mathrm{~cm}^{-2}\right)$ and high ( 2.5 to $3 \times 10^{14} \mathrm{~cm}^{-2}$ ) total neutron fluences are given.

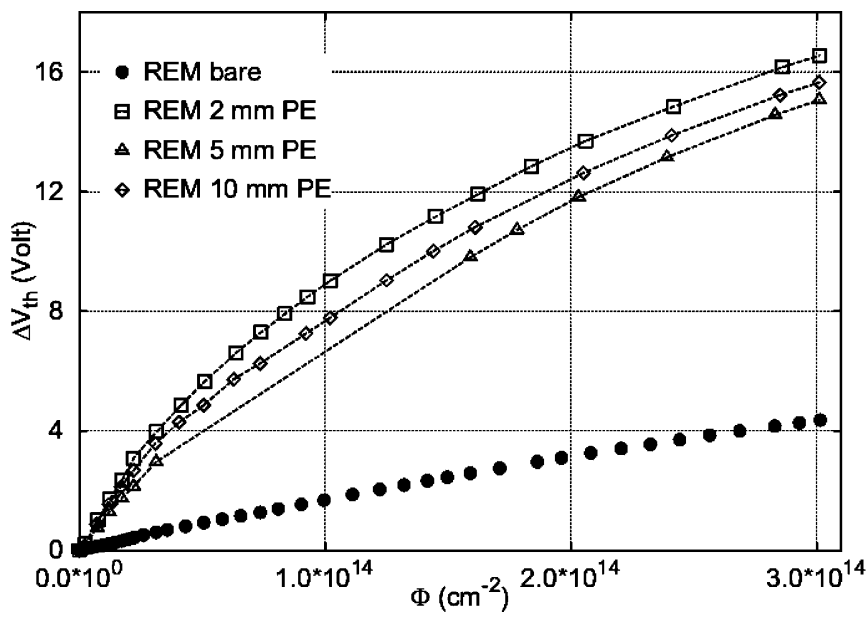

Fig. 5. Comparison between bare die and PE covered REM devices. Devices exposed at $\mathrm{V}_{\mathrm{I}}=0 \mathrm{~V}$.

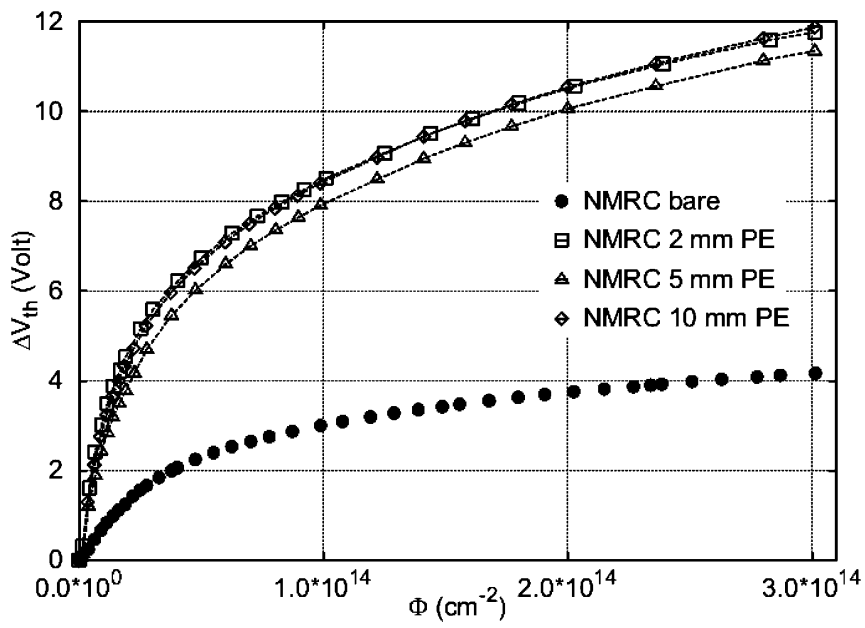

Fig. 6. Comparison between bare die and PE covered NMRC devices. Devices exposed at $\mathrm{V}_{\mathrm{I}}=0 \mathrm{~V}$.

TABLE III

Sensitivity Enhance of PE COVEREd Samples With ResPect to BARE Die ONES. DEVICES EXPoSed AT $\mathrm{V}_{\mathrm{I}}=0 \mathrm{~V}$

\begin{tabular}{ccc}
\hline REM & $\begin{array}{c}\text { Low } \Phi \text { Range } \\
\left(0.5 \text { to } 3 \times 10^{13} \mathrm{~cm}^{-2}\right)\end{array}$ & $\begin{array}{c}\text { High } \Phi \text { Range } \\
\left(2.5 \text { to } 3 \times 10^{14} \mathrm{~cm}^{-2}\right)\end{array}$ \\
\hline $2 \mathrm{~mm} \mathrm{PE}$ & 7.1 & 2.5 \\
$5 \mathrm{~mm} \mathrm{PE}$ & 5.2 & 2.7 \\
$10 \mathrm{~mm} \mathrm{PE}$ & 6.4 & 2.6 \\
\hline & & \\
\hline \multirow{2}{*}{ NMRC } & Low $\Phi$ Range & High $\Phi$ Range \\
& $\left(0.5\right.$ to $\left.3 \times 10^{13} \mathrm{~cm}^{-2}\right)$ & $\left(2.5\right.$ to $\left.3 \times 10^{14} \mathrm{~cm}^{-2}\right)$ \\
\hline $2 \mathrm{~mm} \mathrm{PE}$ & 2.5 & 3.0 \\
$5 \mathrm{~mm} \mathrm{PE}$ & 2.3 & 3.2 \\
$10 \mathrm{~mm} \mathrm{PE}$ & 2.7 & 3.3 \\
\hline
\end{tabular}

\section{GEANT4 SimULATIONS}

To model the influence of the PE absorbers, the particle production from polyethylene slabs was calculated using the GEANT4 simulation tool [9]. In the model, a neutron beam of infinitesimal radius hits perpendicularly polyethylene blocks of $5 \times 5 \mathrm{~cm}^{2}$ surface and with several thicknesses in beam direction. The neutron energy was varying according to a 
TABLE IV

ABUNDANCES OF EJECTED PARTICLE EXCEPT NEUTRONS IN FORWARD DIRECTION FROM GEANT4

\begin{tabular}{cccc}
\hline Particle & \multicolumn{3}{c}{ PE Thickness } \\
\hline & $2 \mathrm{~mm}$ & $5 \mathrm{~mm}$ & $10 \mathrm{~mm}$ \\
\hline Electrons & $2.7 \times 10^{-4} \%$ & $1.2 \times 10^{-3} \%$ & $3.4 \times 10^{-3} \%$ \\
Positrons & $4.3 \times 10^{-5} \%$ & $1.5 \times 10^{-4} \%$ & $4.6 \times 10^{-4} \%$ \\
Protons & $0.64 \%$ & $1.0 \%$ & $1.1 \%$ \\
Photons & $0.035 \%$ & $0.085 \%$ & $0.167 \%$ \\
\hline
\end{tabular}
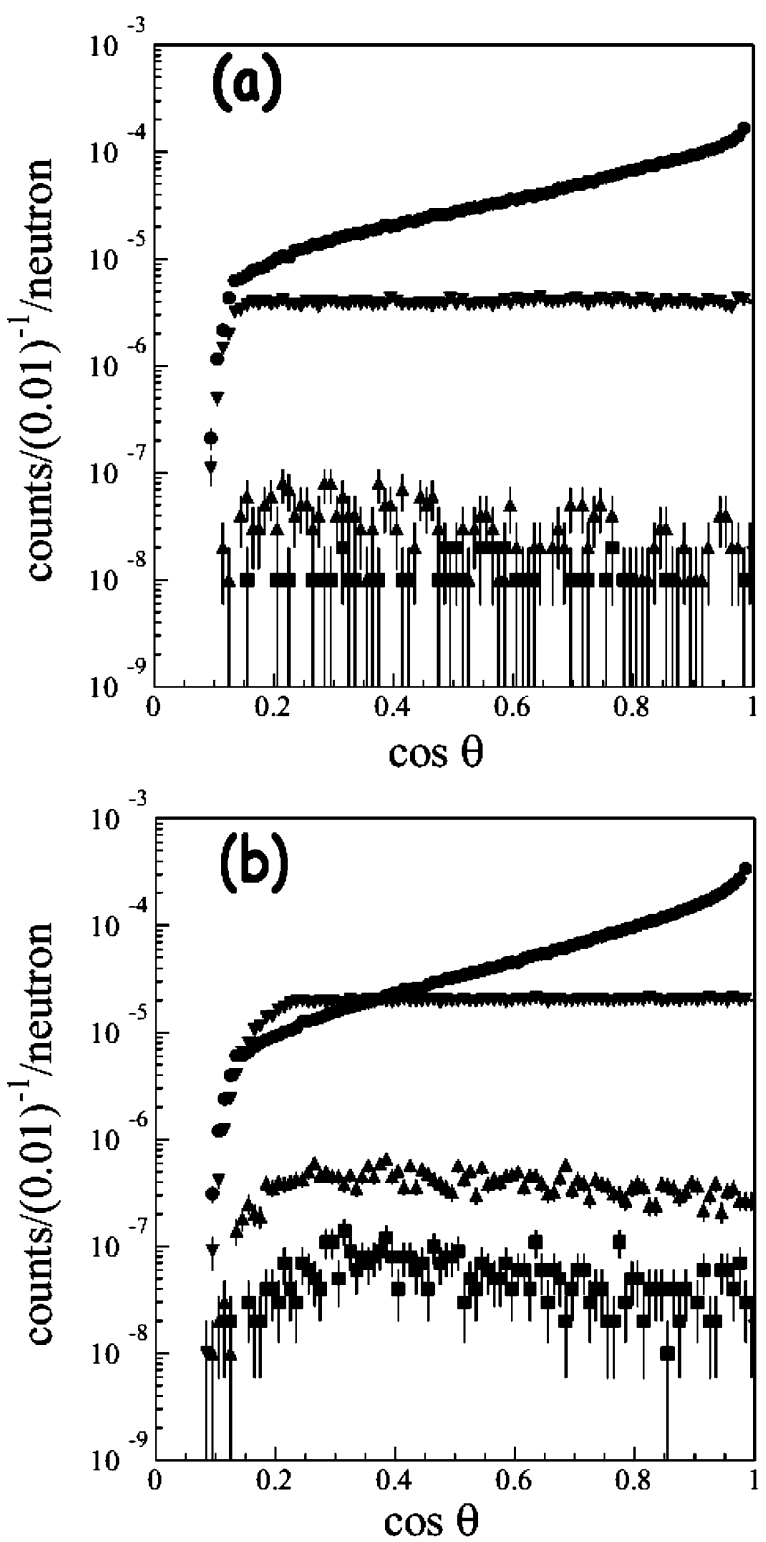

Fig. 7. Angular distributions of all ejected particles simulated for (a) the 2-mm PE slab and (b) for the 10-mm PE slab. From the top to the bottom: proton (round markers), gamma (reverse-triangle markers), electron (triangle markers), and positron (square markers) distributions are plotted, respectively.

Gaussian distribution of a width of $5 \mathrm{MeV}$ around the mean value of $20 \mathrm{MeV}$.

Table IV shows the calculated relative abundances of all particles except neutrons ejected from the polyethylene in forward direction as a function of slab thickness.

Fig. 7 shows the angular distribution of the emitted particles as functions of $\cos \theta$ when $10^{8}$ neutrons are launched on $2 \mathrm{~mm}$

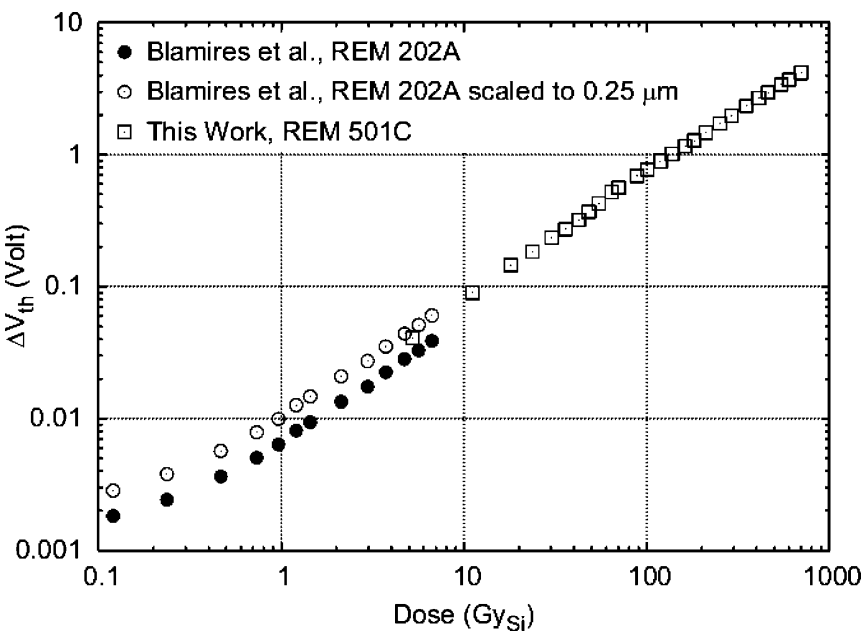

Fig. 8. Comparison with previous data measured by Blamires et al. [10]. Devices exposed at $\mathrm{V}_{\mathrm{I}}=0 \mathrm{~V}$ without plastic converters.

[Fig. 7(a)] and $10 \mathrm{~mm}$ [Fig. 7(b)] PE slabs, respectively. The angle $\theta$ is defined from the direction of the incoming particles. In this reference system the beam direction corresponds thus to an angle $\theta=0$ (i.e., $\cos \theta=1$ as plotted in Fig. 7).

\section{COMPARISON With PREvious Work}

A similar work that was performed on REM RadFETs in metal cans, with $15 \mathrm{MeV}$ monoenergetic neutrons and in a lower dose range, has been reported by Blamires et al. [10].

The REM type was the TOT-202A with an oxide thickness of $\mathrm{t}_{\mathrm{ox}}=0.20 \mu \mathrm{m}$ irradiated with $\mathrm{V}_{\mathrm{I}}=0$. The data are plotted in Fig. 8 as filled circles. Since the oxide thickness of the devices used in this work was $0.25 \mu \mathrm{m}$, the data were rescaled by a factor of

$$
\frac{\Delta V_{t h, T O T-501 C}}{\Delta V_{t h, T O T-202 A}} \propto\left(\frac{t_{\text {ox }, T O T-501 C}}{t_{\text {ox }, T O T-202 A}}\right)^{2}=\left(\frac{0.25}{0.20}\right)^{2}=1.56
$$

taking into account the quadratic dependence of the threshold voltage shift on the oxide thickness [26]. The rescaled data are given as open circles in Fig. 8. As can be seen the data match well with our measurements.

In the dose range below $1 \mathrm{~Gy}_{\mathrm{Si}}$ the sensitivity of the RadFETs seems to be different and not following the power law response explained in Section II-A with an index $b$ close to one. This was interpreted in [10] as an effect of nonstabilized sodium ion movement due to the zero-bias mode $\left(V_{I}=0 \mathrm{~V}\right)$ operation.

\section{DISCUSSION}

\section{A. Comparison of Neutron and Gamma Response}

These experiments confirm what others have predicted [27] and demonstrated [28]; namely, that the RadFET will reliably indicate any ionization which is released within the oxide layer, whatever the nature of the particle which releases it. However, it is known that, RadFETs respond less to particles having high linear energy transfer (LET) such as knock-on protons [29]. Sensitivity to our neutron beam in $\mathrm{mV}$ per unit dose is at least 1.5 times lower than sensitivity to gamma rays. In the low dose range up to about $50 \mathrm{~Gy}$ the reduction is 1.6 (REM) and 2.5 
(NMRC). Similar reduction factors in the order of about two have been reported for similar dose ranges in other work [28], [30] and this is explained by Oldham [29] as enhanced recombination due to high electron-hole density in the particle tracks. The products of $(\mathrm{n}, \mathrm{p})$ and $(\mathrm{n}, \alpha)$ reactions, as calculated in Section IV-B, have LET values well above the level required to give enhanced recombination. As a result, the number of holes trapped per $\mathrm{Gy}$ - and hence the RadFET signal in $\mathrm{mV}$ per Gy-is reduced.

The above statements can be verified taking into account that, in the thick oxide of the NMRC devices exposed with $V_{I}=0 \mathrm{~V}$, the electric field (E) across the oxide layer due to the work function potential [31] is about a factor 2 lower with respect to the REM devices. It has been demonstrated [32] that in a thick oxide the MOSFET's sensitivity is proportional to $\mathrm{E}^{0.7}$. So, in our situation, the reduction factor (ratio of sensitivities to gamma rays versus neutrons) for the NMRC devices is expected to be a factor $2^{0.7} \sim 1.6$ higher with respect to the REM samples. This is in good agreement with our measurements on two Al-gate devices with different oxide thickness values. Thus

$$
\frac{\operatorname{Ratio}_{\frac{\gamma}{n}}(\mathrm{NMRC})}{\operatorname{Ratio}_{n}(\mathrm{REM})} \sim 1.6 .
$$

A notable difference between neutron and gamma responses, as plotted in Fig. 4, is the difference in curve shape under the different types of radiation. For the REM devices (thinner oxide) the absolute threshold voltage shifts for neutron and gamma rays are only slightly different. However, for the NMRC devices (thick oxide) the response curve for the neutrons starts to saturate earlier than for gamma rays and the response above $100 \mathrm{~Gy}_{\mathrm{Si}}$ is near saturation. Given a proper conversion of fluence to dose, we would expect curves from the two types of radiation to coincide quite closely, so there is no obvious mechanism for the mismatch.

A possible explanation for differences in curve shape lies in the profiles of oxide trapped charge in the four cases. This profile can be modified for example by the introduction of new radiation defects in $\mathrm{SiO}_{2}$ by high neutron fluences. Differences in charge profile lead to differences in the profile of the internal field. In turn, these apply different restraining forces on electrons attempting to leave the oxide. In the thinner oxide of the REM devices this effect will be observed later as its initial electric field is $2 \mathrm{x}$ higher. Clearly, the use of RadFETs for neutron dosimetry at high dose requires careful calibration.

\section{B. Influence of the RadFET Packaging}

In Fig. 5 and Fig. 6 the enhancement of dose due to a PE cover, simulating polymeric RadFET packaging, is vividly demonstrated. The PE slabs act as a neutron converter producing recoil protons with energies up to $30 \mathrm{MeV}$, confirming the work of Kronenberg and Brucker for different oxide thicknesses, neutron energies and fluences [28]. The GEANT4 simulation, presented in Section $\mathrm{V}$, demonstrates that the gamma photon fluence is about 10 times lower than the proton fluence while the electron/positron production is negligible. In our experiments, the addition of the PE slabs in the range of
2- to $10-\mathrm{mm}$ increases the neutron sensitivity on average by a factor of 6.2 for the REM devices and by a factor of 2.5 for the NMRC RadFETs for fluences lower than $3 \times 10^{13} \mathrm{~cm}^{-2}$. Further GEANT4 analysis, using more accurate representations of MOSFET structures, may clarify this apparent effect of sensor-layer thickness on charge yield. New simulations should also be based on the full real neutron spectra, with better accuracy in the spectrum below $15 \mathrm{MeV}$ produced by the $\mathrm{Be}(\mathrm{d}$, n)B reaction. Such adjustments will give a better figure for the effectiveness of the PE converters [33].

At higher fluences, the observed differences in the sensitivities of the two device types are possibly driven by the different degree of saturation. However, the enhancement of sensitivity lays around a factor 3.0 for both devices.

The weak dependence on the thickness of the PE slabs was not expected. While GEANT4 predicts over $40 \%$ variation from 2 to $10 \mathrm{~mm}$, the variations observed were instead $15 \%$ for the REM devices and $8 \%$ for NMRC. This unexpected behavior suggests a repeated experiment.

\section{CONCLUSION}

The responses of different RadFET dosimeters over a wide range of fast-neutron fluences were presented extending previously obtained data [10] by two orders of magnitude in dose corresponding to a total neutron fluence of $3 \times 10^{14} \mathrm{~cm}^{-2}$. A reduced sensitivity by a factor of about 2 was measured with respect to gamma ray responses at doses up to $50 \mathrm{~Gy}$ (see Table II). Moreover it was found that at high neutron fluences significantly different sensitivities and strong saturation effects in the RadFET responses due to different gate oxides can arise. These findings lead to the conclusion that the commonly used gamma calibration cannot be directly applied to dose measurements in high-intensity neutron dominated irradiation fields. The situation can be clarified by calculating the enhanced recombination in the sensor oxide layer taking place with low-energy protons and alphas, but differences in curve shapes at high dose are unexplained. Only for low neutron fluences the gamma calibration might be adopted by a scaling factor in order to measure neutron doses. The upper limits of the validity of such scaling vary with oxide thickness.

For the use of RadFETs in radiation fields containing neutrons, gammas and other particles as, e.g., in the planned CERN LHC experiments, special care has to be taken. Of course, the best solution would be to calibrate the RadFETs directly in the mixed irradiation field of interest or a very similar one. However, this is only rarely possible and, therefore, a set of sensitivity versus dose curves for different particle types must be used to estimate the total deposited dose.

It was shown that the presence of a plastic package (here simulated by slabs of polyethylene) on the beam entry side can increase the response to neutrons significantly (a factor of up to 7 was found in this work). While MOSFETs are thought of as "neutron-insensitive," introducing a hydrogenous material gave neutron sensitivity values which were higher than the sensitivity for gamma rays. Using polyethylene slabs of 2, 5, and $10 \mathrm{~mm}$, it was found that even the thinnest layer was sufficient to increase the sensitivity. The variation of the sensitivity in dependence of 
the polyethylene thickness was found to be lower than the $20 \%$ uncertainty of the fluence measurement.

Our experiment confirms that, in the context of the LHC, the mounting of dosimeter-surrounding materials have a significant influence on their response to neutrons. For the development of our radiation sensor this means that, while preliminary calibrations of single dosimeters in individual hadron beams can serve to select operational dosimeters in LHC, dose calibration of the radiation sensor to high accuracy can only be performed with its final design and using the material environment in the array position of the LHC experiments.

\section{ACKNOWLEDGMENT}

The authors wish to thank S. Pospísil from the Institute of Experimental and Applied Physics of the Czech Technical University (IEAP-CTU), Prague for providing the LiPE material, A. Rosenfeld from the University of Wollongong, Australia, M. Huhtinen, C. Joram and E. Tsesmelis from CERN, for valuable comments during the preparation of this article. They would also like to thanks E. Forton from UCL, K. A. Gill from CERN and all the staff and operators of the Cyclotron Research Centre (CRC) for their assistance during the experiments. The support of the mechanical workshop of the CERN TS-LEA group is also gratefully acknowledged.

\section{REFERENCES}

[1] CMS Collaboration, Geneva, Switzerland, "The Compact Muon Solenoid Technical Proposal,”, CERN/LHCC 94-38, LHCC/P1, Dec. 1994.

[2] LHC Experiment Radiation Monitoring Working Group, Geneva, Switzerland. RADMON webpage. [Online]. Available: http://www.cern.ch/lhc-expt-radmon/

[3] M. Huhtinen, "Radiation Environment Simulations for the CMS Detector", Tech. Note 95-198 1995.

[4] F. Ravotti, M. Glaser, M. Moll, K. Idri, J.-R. Vaillé, H. Prevost, and L. Dusseau, "Conception of an integrated sensor for the radiation monitoring of the CMS experiment at the large hadron collider," IEEE Trans. Nucl. Sci., vol. 51, no. 6, pp. 3642-3648, Dec. 2004.

[5] F. Ravotti and M. Glaser, "A Study of the Response of Solid-State Dosimeters to be Used for the Measurement of the Radiation Environment of the CMS Experiment at the LHC," CERN EST, Tech. Note EST-LEA/2003-03, 2003.

[6] B. Camanzi, M. Glaser, E. Tsesmelis, and L. Adams, "A study on the applicability of solid-state, real-time dosimeters to the CMS experiment at the large hadron collider," Nucl. Inst. Meth. A500, pp. 431-440, 2003.

[7] M. Glaser, L. Durieu, F. Lemeilleur, M. Tavlet, C. Leroy, and P. Roy, "New irradiation zones at the CERN-PS," Nucl. Inst. and Meth. A426, pp. 72-77, 1999.

[8] UCL Cyclotron Research Centre webpage. [Online]. Available: http://www.cyc.ucl.ac.be/

[9] GEANT4 Collaboration, "GEANT4-a simulation toolkit," Nucl. Inst. Meth. A506, pp. 250-303, 2003.

[10] N. G. Blamires, D. Totterdell, A. G. Holmes-Siedle, and L. Adams, "pMOS dosimeters: long-term annealing and neutron response," IEEE Trans. Nucl. Sci., vol. 33, no. NS-6, pp. 1310-1315, Dec 1986.
[11] A. G. Holmes-Siedle and L. Adams, "RadFETs: a review of the use of metal-oxide-silicon device as integrating dosimeters," Rad. Phys. Chem., vol. 28, no. 2, pp. 235-244, 1986.

[12] B. Camanzi, A. G. Holmes-Siedle, and A. K. McKemey, "The dose mapping system for the electromagnetic calorimeter of the BaBar experiment at SLAC," Nucl. Inst. Meth. A457, pp. 476-486, 2001.

[13] B. O'Connell, C. Connelly, C. McCarthy, J. Doyle, W. Lane, and L. Adams, "Electrical performances and radiation sensitivity of stacked pMOS dosimeters under bulkbias control," IEEE Trans. Nucl. Sci., vol. 45, pp. 2689-2694, Dec. 1998.

[14] National Microelectronics Research Center, Cork, Ireland. [Online]. Available: http://www.nmrc.ie/projects/radfets/

[15] A. G. Holmes Siedle, L. Adams, and G. Ensell, "MOS dosimeters improvement of responsivity (dosimètres MOS, amélioration de reponsivite)," in Proc. Radiation Effects in Components and Systems Conf. (RADECS 91), Montpellier, France, Sep., 9-12 1991, pp. 65-69.

[16] Thomson and Nielsen (T\&N) website. [Online]. Available: http://www.thomson-elec.com/

[17] J. P. Meulders, P. Leleux, P. Macq, and C. Pirat, "Fast neutron yields and spectra from targets of varying atomic number bombarded with deuterons from 16 to $50 \mathrm{MeV}$," Phys. Med. Biol., vol. 20, p. 235, 1975.

[18] K. Bernier, H. Boukhal, J.-M. Denis, T. Bardouni, G. Grégoire, O. Grégoire, and V. Tran, "An Intense Fast Neutron Beam in Louvain-la-Neuve," [Online]. Available: http://www.fynu.ucl.ac.be/ themes/he/cms/.

[19] S. Pospisil, J. Kubasta, I. Stekl, and V. Vrba, "Comparison of efficiencies of neutron shields containing boron and lithium", Internal Note TECH-No-016, 1995.

[20] S. Pospisil, I. Stekl, T. Cechak, J. Jakubek, J. Kluson, J. Konicek, V. Linhart, M. Sinor, and C. Leroy et al., "Experimental tests of neutron shielding in the ATLAS forward region", ATLAS Internal Note TECH-No-028, 1997.

[21] S. Agosteo, S. Alteri, G. Belli, and A. Bonifas et al., "A facility for test of large-area muon chambers at high rates," Nucl. Instrum. Meth. A452, pp. 94-104, 2000.

[22] PTW Dosimetry Systems and Ionization Chambers for Radiation Measurement website. [Online]. Available: http://www.ptw.de

[23] A. G. Holmes-Siedle, "REM," unpublished, 2003.

[24] A. Jaksic, "NMRC," unpublished, 2002.

[25] A. G. Alekseev, E. N. Savitskaya, S. A. Kharlampiev, and I. A Kurochkin, "Dose characteristics of high-energy neutrons for radiation damage evaluation of silicon semiconductor devices", in CERN Health Physics and Radiation Effects Preprint, IHEP 94-65, 1994.

[26] A. G. Holmes-Siedle and L. Adams, Handbook of Radiation Effects, 2nd ed. Oxford, U.K.: Oxford Univ. Press, 2002.

[27] L. S. August, "Estimating and reducing errors in MOS dosimeters caused by exposure to different radiations," IEEE Trans. Nucl. Sci., vol. 29, no. 6, pp. 2000-2003, 1982.

[28] S. Kronenberg and G. J. Brucker, "The use of hydrogenous material for sensitizing pMOS dosimeters to neutrons," IEEE Trans. Nucl. Sci., vol. 42, no. 1 , pp. 20-26, 1995.

[29] T. R. Oldham, Ionizing Radiation Effects in MOS Oxides, Singapore: World Scientific, 2000.

[30] R. Pease, M. Simons, and P. Marshall, "Comparison of pMOS total dose response for Co-60 gammas and high-energy protons," IEEE Trans. Nucl. Sci., vol. 48, no. 3, pp. 908-912, Jun. 2001.

[31] B. E. Deal, E. H. Snow, and C. A. Mead, "Barrier energies in metal-silicon dioxide-silicon structures," J. Phys. Chem. Solids, vol. 27, p. 1873, 1966.

[32] M. G. Carolan, "Semiconductor dosimetry of epithermal neutron beams for boron neutron capture therapy," Ph.D. thesis, Dept. Eng. Phys., Univ. Wollongong, New South Wales, Australia, 2003.

[33] M. Cornelius and A. Rosenfeld, "Verification of Monte Carlo calculations in fast neutron therapy using silicon microdosimetry," IEEE Trans. Nucl Sci, vol. 51, no. 3, pp. 873-877, Jun. 2004. 